\title{
Manganese Superoxide Dismutase Gene Polymorphism and Schizophrenia: Relation to Tardive Dyskinesia
}

Hiroko Hori, M.D., Osamu Ohmori, M.D., Ph.D., Takahiro Shinkai, M.D., Hideki Kojima, M.D., Chie Okano, Takashi Suzuki, M.D., Ph.D., and Jun Nakamura, M.D., Ph.D.

There has been increasing evidence that deranged superoxide dismutase (SOD) activities might be a risk factor for schizophrenia and/or tardive dyskinesia (TD). In the present study, we investigated the genetic association between a functional polymorphism (Ala-9Val) in the human manganese $(\mathrm{Mn}) \mathrm{SOD}$ gene and schizophrenia or TD (192 schizophrenics : 39 with TD and 153 without TD; 141 controls). No significant differences in the allelic or genotypic distribution between schizophrenics and controls were observed. However, we did find a significant difference in genotypic distribution between schizophrenics with and those without TD $(\mathrm{p}=.03)$. Moreover, decreased -9 Ala (mutant) allele was found among patients with $T D(\mathrm{p}=$ $.02 ;$ odds ratio $=0.29 ; 95 \%$ confidence interval $=0.10$ 0.83). In conjunction with previous findings of increased free radicals and decreased SOD activities in TD subjects, these results suggest that the-9Ala (high activity) $M n S O D$ allele may play a role in protecting against susceptibility to TD in schizophrenics.

[Neuropsychopharmacology 23:170-177, 2000] (C) 2000 American College of Neuropsychopharmacology. Published by Elsevier Science Inc. All rights reserved
KEY WORDS: Superoxide dismutase; Schizophrenia; Tardive dyskinesia; Polymorphism; Association study

There has been increasing evidence that free radicalmediated CNS neuronal dysfunction is involved in the pathophysiology of schizophrenia: for example, antioxidant enzyme levels have been shown to be altered in the red blood cells (RBC) of schizophrenic patients (Reddy et al. 1991; Mukherjee et al. 1996). Lipid peroxidation, which is produced when free radicals damage membranes or free lipids, is known to be increased in the cerebrospinal fluid (CSF) and in the plasma of patients with schizophrenia (Mahadik et al. 1995). Mem-

From the Department of Psychiatry, School of Medicine, University of Occupational and Environmental Health, Kitakyushu, Japan.

Address correspondence to: Hiroko Hori, Department of Psychiatry, University of Occupational and Environmental Health, Yahatanishi-ku, Kitakyushu, 807-8555, Japan.

Received August 9, 1999; revised November 30, 1999; accepted December 3, 1999. brane polyunsaturated fatty acids (PUFAs), which are oxyradical sensitive, are known to be reduced in the brain and RBC plasma membranes in patients with schizophrenia (Horrobin et al. 1991).

Several lines of evidence have indicated that free radicals may play a role in the pathophysiology of tardive dyskinesia (TD). It has been reported that free radicals, especially superoxide radicals, are produced by the increased dopamine turnover associated with longterm neuroleptic treatment (Matsumoto et al. 1983). In a study by Pall et al. (1987), CSF lipid peroxidation was increased in patients taking phenothiazine. Lohr et al. (1990) reported that free radical activity was higher in patients with TD than in those without. These findings have led to therapeutic trials with $\alpha$-tocopherol (vitamin E), a free radical scavenging agent, in patients with TD; the anecdotal reports have been confirmed by double-blind, placebo-controlled studies with vitamin $\mathrm{E}$ (Egan et al. 1992; Adler et al. 1993; Lohr and Caligiuri 1996). 
Since the metalloprotein superoxide dismutase, $\mathrm{SOD}$, is the key enzyme involved in the detoxification of superoxide radicals, it may play a vital role in interindividual variation in superoxide radical turnover. SOD activities in RBC have been found to be altered in chronic schizophrenic patients (Reddy et al. 1991; Mukherjee et al. 1996), though it is unclear whether there is a fundamental deregulation of SOD in schizophrenia or whether these activities reflect effects of long-term neuroleptic treatment. However, it has recently been reported that SOD activity was significantly lower in 14 drug-naive patients than in normal controls (Mukherjee et al. 1996). In addition, patients with TD have shown to have low SOD activities compared to those without TD (Yamada et al. 1997; Tsai et al. 1998). These findings indicate that the compromised antioxidant defense associated with deranged SOD activities may constitute a risk factor for schizophrenia and/or TD.

There are three isoforms of SOD which contain different prosthetic groups: the manganese $(\mathrm{Mn})$ isoform (SOD2) is found in mitochondria, and the copper and zinc $(\mathrm{CuZn})$ isoforms are present in the cytoplasm (SOD1) as well as in the extracellular space (SOD3). Among these isoforms of SOD, the manganese $(\mathrm{Mn})$ isoform (MnSOD or SOD2) scavenges the greatest number of superoxide anions produced from the electron transport systems in mitochondria, which account for more than $95 \%$ of all oxygen consumption in aerobic cells (Guidot et al. 1993).

Recently, Shimoda-Matsubayashi et al. (1996) found a biallelic polymorphism (Ala-9Val) in the mitochondrial targeting sequence (MTS) of human MnSOD in a Japanese population and reported a significant positive association between the MnSOD allele and Parkinson's disease. The Val substitution at position -9 of the MTS of human MnSOD may lead to misdirected intracellular trafficking, followed by the alteration of MnSOD activity in human mitochondria (Shimoda-Matsubayashi et al. 1997).

In this study, we investigated the genetic association of the MnSOD allele with schizophrenia and TD in a Japanese sample through case-control studies.

\section{SUBJECTS AND METHODS}

\section{Subjects}

One hundred-ninety-two Japanese schizophrenic patients participated in this study. Assessment for diagnosis of schizophrenia using DSM-IV criteria was performed by four psychiatrists with consensus, and based on cross-sectional interviews and case records. None of the subjects had significant neurological comorbidity, epilepsy, mental retardation, or history of substance abuse. All patients had received neuroleptic treatment for at least 10 years. Their ages (mean, 55.61 years; $\mathrm{SD}=$
9.06), gender (95 men, 97 women), duration of illness (mean duration, 28.80 years; SD = 9.26), and current neuroleptic dosages, which were calculated into haloperidol equivalents according to the conversions published by Toru (1983) (mean dose of haloperidal equivalents, $23.34 \mathrm{mg} /$ day; $\mathrm{SD}=24.14$ ), were evaluated from clinical records.

The neuroleptics most prescribed were haloperidol $(n=103$; mean dose, $15.93 \mathrm{mg} /$ day; $\mathrm{SD}=13.95)$, levomepromazine ( $n=78$; mean dose, $106.19 \mathrm{mg} /$ day; $\mathrm{SD}=64.70)$, bromperidol $(n=48$; mean dose, 13.96 $\mathrm{mg} /$ day; $\mathrm{SD}=9.11)$, chlorpromazine $(n=42$; mean dose, $106.19 \mathrm{mg} /$ day; $\mathrm{SD}=154.86)$, zotepine $(n=31$; mean dose, $160.65 \mathrm{mg} /$ day; $\mathrm{SD}=108.71)$, propericiazine $(n=23$; mean dose, $74.13 \mathrm{mg} /$ day; $\mathrm{SD}=46.36)$, sulpiride $(n=22$; mean dose, $288.18 \mathrm{mg}$ /day; $\mathrm{SD}=$ 160.05), and mosapramine ( $n=20$; mean dose, 130.00 $\mathrm{mg} /$ day; $\mathrm{SD}=41.53$ ). One hundred-fifty-four out of 192 patients received a polypharmacy of neuroleptics. In addition, 169 patients received one $(n=115)$, two $(n=$ $51)$, or three $(n=3)$ of the anti-parkinsonian drugs, biperiden $(n=109$; mean dose, $3.27 \mathrm{mg} /$ day; $\mathrm{SD}=1.23)$, prometazine $(n=56$; mean dose, $42.06 \mathrm{mg} /$ day; $\mathrm{SD}=$ 23.61), trihexyphenidyl ( $n=41$; mean dose, $5.41 \mathrm{mg} /$ day; $\mathrm{SD}=2.61)$, mazaticol $(n=10$; mean dose, 14.00 $\mathrm{mg} /$ day; $\mathrm{SD}=5.73)$, and profenamine $(n=10$; mean dose, $160.00 \mathrm{mg} /$ day; $\mathrm{SD}=58.31$ ).

One hundred forty-one healthy volunteers (71 males and 70 females; mean age, 55.33 years; $\mathrm{SD}=6.81$ ) were recruited mostly from medical staffs as control subjects. Only unaffected subjects whose first- and seconddegree relatives had no history of schizophrenia or other psychiatric disorders were included in this study. All controls were over 45 years-of-age because of the relatively low frequency of schizophrenia after age 45 .

All patients had been admitted to one of five hospitals within $30 \mathrm{~km}$ radius of the University of Occupational and Environmental Health; the controls also lived within this area. All subjects in this study were unrelated Japanese originally from the northern part of Kyushu Island, Japan. Informed consent was a premise for participation, and this study was approved by the Ethics Community of the University of Occupational and Environmental Health.

\section{Symptom Analysis}

TD was evaluated in all patients using the Abnormal Involuntary Movement Scale (AIMS) (Guy 1976). We rated the first seven items to determine a severity of abnormal movement score for each of seven respective regions of the body by a cross-sectional evaluation. When a patient had one or more 3-point, or, two or more 2-point in seven AIMS items mentioned above, he/she was considered to have TD. The others were assumed not to have TD (Schooler and Kane 1982). All evalua- 
tions were carried out by the same experienced psychiatrist prior to the laboratory procedures.

\section{Genetic Analysis}

Genomic DNA was extracted from 10-ml aliquots of EDTA-anticoagulated venous blood using standard procedures. A genomic DNA fragment corresponding to the MTS in the human MnSOD sequence was amplified by the polymerase chain reaction (PCR) method, using specific primers as described by Shimoda-Matsubayashi et al. (1996). The PCR products (172 bp) were digested with BsaWI and then electrophoresed on 3\% agarose gels. The polymorphism showed a biallelic system, T/C. The $-9 \mathrm{Val}$ allele showed DNA fragments of $85 \mathrm{bp}$ and $87 \mathrm{bp}$, whereas the -9Ala allele PCR products remained uncut with a DNA fragment of $172 \mathrm{bp}$.

\section{Statistical Analysis}

The fitness of genotypic distribution to the HardyWeinberg equilibrium was analyzed by the $\chi^{2}$ goodness-of-fit test. Differences of genotypic distributions between patients and controls, as well as between patients with TD and without TD, were evaluated by Monte Carlo methods to evaluate the contingency table with small cell counts (Sham and Curtis 1995). Differences of allelic distribution between patients and controls, as well as between patients with TD and without TD, were analyzed using the Fisher's exact test. Differences in the demographic characteristics of patients, age, duration of neuroleptic treatment, current neuroleptic dose, and total AIMS scores were assessed among the three MnSOD genotypes using one-way analyses of variance (ANOVA). Because the distribution of total AIMS scores of the three MnSOD genotypes was skewed, we assessed the scores using the Kruskal-Wallis test. Gender differences were assessed by the Monte Carlo method.

The genotypic association between the MnSOD genotype and TD was adjusted simultaneously for potentially confounding variables (gender, age, duration of illness, and neuroleptic dose) using regression analysis. Occurrence of TD and total AIMS score were suited for a stepwise logistic and a multiple regression analysis, respectively. Data analyses were computed with the SPSS software package throughout.

\section{RESULTS}

Allele and genotype frequencies of samples for the Ala-9Val polymorphism in the MnSOD gene are given in Table 1. The genotypic distributions in both patients and controls were within the Hardy-Weinberg equilibrium. There was no significant difference in the distri-
Table 1. Genotype and Allele Frequencies of the Ala 9Val Polymorphism in Patients and Controls

\begin{tabular}{|c|c|c|c|c|c|}
\hline & \multicolumn{3}{|c|}{ Genotypes $^{a}$} & \multicolumn{2}{|c|}{$\begin{array}{c}\text { Allele } \\
\text { Frequency }^{b}\end{array}$} \\
\hline & $\begin{array}{c}\text { Ala/Ala } \\
n(\%)\end{array}$ & $\begin{array}{c}\mathrm{Ala} / \mathrm{Val} \\
n(\%)\end{array}$ & $\begin{array}{c}\text { Val/Val } \\
n(\%)\end{array}$ & -9Ala & $-9 \mathrm{Val}$ \\
\hline Patients $(n=192)$ & $3(1.6)$ & $39(20.3)$ & $\begin{array}{c}150 \\
(78.1)\end{array}$ & 0.12 & 0.89 \\
\hline Controls $(n=141)$ & $2(1.4)$ & 27 (19.2) & $\begin{array}{c}112 \\
(79.4)\end{array}$ & 0.11 & 0.89 \\
\hline
\end{tabular}

${ }^{a}$ No significant difference in genotype frequencies between patients and controls $\left(\chi^{2}=0.08, \mathrm{df}=2, p=.96\right)$.

${ }^{b}$ No significant difference in allele frequencies between patients and controls (Fisher's exact test, 2 tailed, $p=1.00$, odds ratio $=1.07 ; 95 \%$ confidence interval 0.66-1.73).

bution of the allele (Fisher's exact test, 2 tailed, $p=1.00$, odds ratio $=1.07,95 \%$ confidence interval $=0.66-1.73$ ), and genotype frequencies $\left(\chi^{2}=0.08, \mathrm{df}=2, p=.96\right)$ between patients and controls.

Demographic characteristics of patients in the MnSOD genotype group are shown in Table 2. There was no significant difference in terms of age, gender, duration of illness, or current neuroleptic dose among the three genotype groups. Total AIMS scores (mean \pm SD) in patients with the three MnSOD genotypes were $0.00 \pm$ 0.00 (Ala/Ala), $1.49 \pm 2.04$ (Ala/Val), and $2.27 \pm 2.85$ (Val/Val). Although patients with the $\mathrm{Val} / \mathrm{Val}$ genotype tended to have higher AIMS scores, this trend did not reach the level of statistical significance $(p=.08)$.

Thirty-nine of the 192 patients $(20.3 \%)$ were diagnosed as having TD (Table 3). There was a significant difference in genotypic distribution $\left(\chi^{2}=5.86, \mathrm{df}=2\right.$, $p=.04$ ) between patients with and without TD. The -9 Val allele was more common in the patients with TD than in those without TD (Fisher's exact test, 2 tailed, $p=.02$, odds ratio $=0.29,95 \%$ confidence interval $=$ $0.10-0.83$ ).

When the MnSOD genotype, gender, age, duration of illness, and neuroleptic dose were entered into regression models as independent variables (Table 4), we found significant associations of the occurrence of TD with Ala-9Val genotype $(p=.03)$ and age $(p<.001)$. The total AIMS score was significantly associated with age $(p<.001)$ and duration of illness $(p<.001)$. There was a slight but non significant association between the total AIMS score and the Ala-9Val genotype $(p=.08)$. We next performed a regression analysis using a forward stepwise procedure $(p$ to enter $=.05 ; p$ to remove $=$ .1). The results were as follows. In the stepwise logistic model, age ( $p=.001)$ was entered first and genotype ( $p=$ .03) was entered subsequently. The rest of the variables were removed from the model. In the multiple regression model, age $(p<.001)$ was entered first and duration of illness $(p<.001)$ was entered subsequently. The 
Table 2. Demographic Characteristics of Patients in the MnSOD Genotype Groups

\begin{tabular}{lccc}
\hline & \multicolumn{3}{c}{ Genotype } \\
\cline { 2 - 4 } Characteristic & Ala/Ala $(\boldsymbol{n}=\mathbf{3})$ & Ala/Val $(\boldsymbol{n}=\mathbf{3 9 )}$ & Val/Val $(\boldsymbol{n}=\mathbf{1 5 0})$ \\
\hline Gender (F/M) & $1 / 2$ & $16 / 23$ & $80 / 70$ \\
Age (years) & $50.67 \pm 2.52$ & $55.28 \pm 9.17$ & $.38^{* *}$ \\
Duration of illness (years) & $30.67 \pm 4.16$ & $29.41 \pm 9.90$ & .61 \\
Current neuroleptic dose (HPD-eq; mg/day) & $23.20 \pm 16.62$ & $20.95 \pm 29.17$ & $28.61 \pm 9.15$ \\
Total AIMS score & $0.00 \pm 0.00$ & $1.49 \pm 2.04$ & $23.97 \pm 22.97$ \\
\end{tabular}

Values are given as mean $\pm \mathrm{SD}$ or number.

F: female; M: male.

HPD-eq: haloperidol equivalents.

${ }^{*} p$ values determined by ${ }^{* *}$ Monte Carlo method, ${ }^{* * *}$ Kruskal-Wallis test, or, if unmarked, ANOVA.

rest of the variables, including the MnSOD genotype, were removed from the model. Therefore, the MnSOD genotype was forced into the model and was not associated with the total AIMS score $(p=.11)$.

We estimate that the sample has a power of 1.00 to detect a medium effect size $(\mathrm{w}=0.25)$ and of 0.44 to detect a small effect size $(\mathrm{w}=0.10)$ at the $p<.05$ level for allelic comparison with the $\chi^{2}$ test between patients and controls using SPSS Sample Power software for Windows. We also estimate that the sample has a power of 0.99 to detect a large effect size $(w=0.38)$, of 0.8 to detect a medium effect size, and of 0.20 to detect a small effect size at the $p<.05$ level for allelic comparison with the $\chi^{2}$ test between patients with and without TD.

\section{DISCUSSION}

In the present study, we assessed the relationship between schizophrenia and free radicals, focusing on MnSOD, which is involved in the antioxidant defense system. We assumed that oxidative injury caused by the impaired antioxidant enzyme MnSOD, might contribute to adverse development events in the pathogenic cascade of schizophrenics. However, no association was found between the Ala-9Val polymorphism of the MTS in the MnSOD gene and schizophrenia in our sam- ple. Our present findings thus indicate that the polymorphism in the MnSOD gene may not contribute directly to the susceptibility to schizophrenia.

TD occurs as a side effect of neuroleptic medication. Several risk factors for TD, such as dosage and potency of neuroleptic drugs (Casey 1991), duration of neuroleptic treatment (Sweet et al. 1995), age (Miller et al. 1995), and female gender (Kane and Smith 1982) have been pointed out. In addition, genetic predisposition is thought to confer susceptibility to TD. A recent study reported the concordance for the presence or absence of TD in 13 out of 16 relative pairs (Müller et al. 1998). Moreover, several recent case-control association studies have demonstrated that the dopamine D3 receptor gene (Steen et al. 1997) and debrisoquine 4-hydroxylase (CYP2D6) gene (Armstrong et al. 1997; Ohmori et al. 1998) may be implicated in susceptibility to TD. In addition to the above mentioned risk factors of TD, we assumed that the derangement of the MnSOD enzyme may also be involved in susceptibility to TD.

We found significant associations, both genotypic and allelic, between the Ala-9Val polymorphism in the MnSOD gene and the occurrence of TD. The $-9 \mathrm{Val}$ allele was more frequent in patients with TD than in those without. The significance remained when the confounding variables (gender, age, duration of illness, and neuroleptic dose) were adjusted by stepwise logistic

Table 3. Genotype and Allele Frequencies of the Ala-9Val Polymorphism in Subjects with and without TD

\begin{tabular}{|c|c|c|c|c|c|}
\hline & \multicolumn{3}{|c|}{ Genotype $^{a}$} & \multirow{2}{*}{\multicolumn{2}{|c|}{ Allele frequency ${ }^{b}$}} \\
\hline & \multirow{2}{*}{$\begin{array}{c}\text { Ala/Ala } \\
n(\%)\end{array}$} & \multirow{2}{*}{$\begin{array}{c}\mathrm{Ala} / \mathrm{Val} \\
n(\%)\end{array}$} & \multirow{2}{*}{$\begin{array}{c}\text { Val/Val } \\
n(\%)\end{array}$} & & \\
\hline & & & & -9 Ala & $-9 \mathrm{Val}$ \\
\hline \multicolumn{6}{|c|}{$\begin{array}{l}\text { Diagnostic criteria from AIMS } \\
\left(\text { two ' } 2 s^{\prime} \text { or one ' } 3 \text { ') }\right.\end{array}$} \\
\hline With TD $(n=39)$ & $0(0)$ & $3(7.7)$ & $36(92.3)$ & 0.04 & 0.96 \\
\hline Without TD $(n=153)$ & $3(2.0)$ & $36(23.5)$ & $114(74.5)$ & 0.15 & 0.86 \\
\hline
\end{tabular}

\footnotetext{
${ }^{a}$ Significant difference in genotype frequency between patients with and without $\operatorname{TD}\left(\chi^{2}=5.86, \mathrm{df}=2, p=.04\right)$.

${ }^{b}$ Significant difference in allele frequency between patients with and without TD (Fisher's exact test, 2 tailed, $p=.02$; odds ratio $=0.29 ; 95 \%$ confidence interval 0.10-0.83).
} 
Table 4. Regression Analysis (before Forward Stepwise Procedure) with Occurrence of TD or Total AIMS Score as Dependent Variable

\begin{tabular}{|c|c|c|c|c|}
\hline \multirow[b]{3}{*}{ Independent variables } & \multicolumn{4}{|c|}{ Dependent variables } \\
\hline & \multicolumn{2}{|c|}{$\begin{array}{l}\text { With versus without TD } \\
\text { (stepwise logistic model) }\end{array}$} & \multicolumn{2}{|c|}{$\begin{array}{c}\text { Total AIMS score } \\
\text { (multiple regression model) }\end{array}$} \\
\hline & Parameter estimate & $p$ & Parameter estimate & $p$ \\
\hline Ala - 9Val genotype & -14.42 & .03 & -0.71 & .08 \\
\hline Age (years) & 0.11 & .00 & 0.15 & .00 \\
\hline Duration of illness (years) & -0.05 & .08 & -0.10 & .00 \\
\hline Current neuroleptic dose (HPD-eq; mg/day) ${ }^{a}$ & 0.00 & .92 & 0.00 & .88 \\
\hline Gender & -0.59 & .20 & -0.71 & .15 \\
\hline
\end{tabular}

${ }^{a}$ HPD-eq: haloperidol equivalents.

analysis. These findings suggest that the $-9 \mathrm{Val}$ allele may be a risk factor of TD. However, the $-9 \mathrm{Val}$ allele is thought to be a wild type allele, while the -9Ala allele is thought to be a mutant allele. In fact, the $-9 \mathrm{Val}$ allele was more common, with an allele frequency of 0.89 , than the -9Ala allele, with a frequency of 0.12 , in patients in the present study. Consequently, it may be difficult to interpret these findings. One interpretation of the results might be that another unknown polymorphism, which is in linkage disequilibrium with the Val-9Ala polymorphism and contributes susceptibility to $\mathrm{TD}$, exists in the MnSOD gene. Another functional polymorphism of the MnSOD gene, Ile58Thr at exon 3, has been reported by Borgstahl et al. (1996). Because the 58Thr allele, however is extremely rare (Grasbon-Frodl et al. 1999). Thus, further studies will be needed to detect another functional polymorphism which is more suitable for use in association studies.

Another interpretation is that the -9Ala allele may play a role in protecting against TD, based on the relatively lower frequency of this allele in subjects with than in those without TD. This assumption is consistent with the finding that the Val/Val genotype tended to have higher total AIMS scores, although the trend did not reach the level of statistical significance. Furthermore, the finding, by several authors, of increased free radicals and decreased SOD activities in patients with TD (Lohr et al. 1990; Yamada et al. 1997; Tsai et al. 1998) are also consistent with our assumption through following reports that the -9Ala allele may result in higher MnSOD activity. It has been reported that the -9Ala allele of MTS of the MnSOD gene has an $\alpha$-helix structure, whereas the $-9 \mathrm{Val}$ allele does not (ShimodaMatsubayashi et al. 1996). Because an amphiphilic helix structure is an essential requirement for efficient mitochondrial transport, the MnSOD precursor protein with the -9Ala-type signal peptide may be more easily transported into mitochondria than the precursor with the -9Val-type signal peptide. Therefore, the difference in the signal peptide sequence may affect the amount of
MnSOD expressed within mitochondria (Shimoda-Matsubayashi et al. 1997). It has also been reported that a Lewy body-negative familial Parkinson's disease patient with homozygotes of Ala/Ala had a higher concentration of SOD than patients with heterozygotes of Ala/Val or homozygotes of Val/Val (Shimoda-Matsubayashi et al. 1997). These findings, in conjunction with the relatively lower frequency of the -9Ala (high activity) allele in patients with TD in our study, suggest that patients without TD may show higher MnSOD activity and may be more capable of detoxifying superoxide radicals than those with TD. Moreover, SOD has been found to protect against neuronal degeneration induced by the glutamatergic mechanism (Schwarts et al. 1998), which is thought to be relevant to the pathophysiology of TD (Tsai et al. 1998).

In the present study, we have confirmed that the occurrence of TD relates to age and duration of illness (Table 4). However, current neuroleptic dose and gender were not associated with the occurrence of TD. Latimer (1995) suggested that age is more consistently identified as a risk factor for TD than are such other risk factors as current neuroleptic dose and female gender. In addition, Miller et al. (1995) have shown that only age, but gender and daily neuroleptic dose, had a significant influence on the development of TD in chronic psychiatric patients. We do not consider our results inconsistent with these observations, since the aging may have contributed to the duration of illness in our patients.

Based on the results of the present study, we believe that the reason the -9 Ala allele was more associated with a low risk for TD development than the $-9 \mathrm{Val}$ allele, was that the former may induce higher MnSOD activity, thereby leading to an increased capacity for defense against antioxidant. However, the function of MnSOD seems more complicated; it also has an ability to produce hydrogen peroxide which in turn may react with ferrous iron to form more cytotoxic hydroxyl radicals (Gutteridge 1992). Shimoda-Matsubayashi et al. 
$(1996,1997)$ reported that the -9 Ala allele was more frequent in patients with Parkinson's disease than in controls, and also that higher-than-normal activity of MnSOD induces oxidative stress and may be a genetic risk factor for Parkinson's disease. This view is inconsistent with our suggestion that the decreased -9Ala (high activity) allele frequency among patients with TD may reflect a decreased capacity for defense against antioxidants. On the other hand, our results are compatible with previous reports that patients with TD had a lower SOD activity than those without TD (Yamada et al. 1997; Tsai et al. 1998). However, these reports have not shown the relationship between specific MnSOD activity and the occurrence of TD. Further studies will be needed to clarify this relation.

The genetic contribution of the Ala-9Val polymorphism in the MnSOD gene to TD was relatively weak in the present study. The frequency of the -9Ala allele among subjects without TD was only 0.25 , and thus the protective effect of this allele against TD must be small. Our earlier study (Ohmori et al. 1998) demonstrated a nominal significant allelic association $(p=.049$, odds ratio $=1.98,95 \%$ confidence interval $=1.01-3.87)$ between the CYP2D6 gene polymorphism and TD. A study by Steen et al. (1997) on the genetic association between the Ser9Gly polymorphism of the dopamine D3 receptor gene and TD also showed relatively weak associations between the Gly allele and TD $(p=.035$, odds ratio $=2.20,95 \%$ confidence interval $=1.05-3.97)$ or between homozygosity for the Gly allele and TD $(p=$ .018 , odds ratio $=6.46,95 \%$ confidence interval $=1.28$ 62.36). Segman et al. (1999) replicated this study and found no significant difference in allelic distribution between schizophrenics with and without TD, although genotypes containing the Gly allele (Gly/Gly and Gly / Ser) were significantly associated with TD $(p=.02$, odds ratio $=2.62,95 \%$ confidence interval $=1.18-5.59$ ). Thus, none of the above-described genetic association studies of TD have detected any genes having a major impact on susceptibility to TD. The major complicating factor in the identification of such genes is that the primary etiological factor is environmental, namely, exposure to neuroleptics. Compared to this effect, genes may play a relatively small role in causation (Jeste and Kelsoe 1997).

Although the case-control association studies employed here are potentially useful tools for the study of complex psychiatric diseases, as well as of complex side effects such as TD (Jeste and Kelsoe 1997), one major pitfall of such studies is the vulnerability to ethnic stratification between subjects groups (Malhotra and Goldman 1999). The present sample, in contrast, considered exclusively of Japanese subjects who were considered to be from ethnically homogeneous populations. We further restricted our sample to subjects from the same area in the northern part of Kyushu Island, Japan in or- der to minimize their internal heterogeneity. Nonetheless, there may have remained an unexpected sample stratification which could have led to artifacts in the results.

We also attempted to investigate the possible association between a polymorphism of the CuZnSOD gene and susceptibility to schizophrenia or TD. We genotyped 50 patients with schizophrenia for an A/C polymorphism in intron 3 of the CuZnSOD gene, which has been studied by Esteban et al. (1994). Nonetheless, no subject with a variant was identified in our samples. Consequently, we could not carry out the association study between the CuZnSOD gene polymorphism and TD in our sample.

In conclusion, we did not find a significant association between Ala-9Val polymorphism in the MnSOD gene and schizophrenia; however, we did find one between the polymorphism and the occurrence of TD. That is, there was a decrease in the frequency of -9Ala allele in patients with TD as compared to those without TD. These results suggested that the -9Ala allele may help protecting against the occurrence of TD by enhancing MnSOD activity. At the same time, however, MnSOD has the ability to produce cytotoxic hydroxyl radicals, which can damage brain tissue (Gutteridge 1992). Other enzymes involved in the antioxidant defense system should thus be taken into account, including $\mathrm{CuZn-}$ SOD, glutathione peroxidase, and catalase. In addition, it is important to remember the limitations of case-control association studies, especially their vulnerability to sample stratification, which may provide false positive results. In view of these limitations in our study, further studies will be needed to confirm our results.

\section{ACKNOWLEDGMENTS}

We wish to thank Dr. Akira Etoh, Dr. Yoshitaro Mine, Dr. Yasuhiro Tsutsumi, Dr. Kenji Yamaura, and Dr. Takaharu Hayashida for providing the patient information.

\section{REFERENCES}

Adler LA, Peselow E, Rotrosen J, Duncan E, Lee M, Rosenthal M, Angrist B (1993): Vitamin E treatment of tardive dyskinesia. Am J Psychiatry 150:1405-1407

Armstrong M, Daly AK, Blennerhassett R, Ferrier N, Idle JR (1997): Antipsychotic drug-induced movement disorders in schizophrenics in relation to CYP2D6 genotype. Br J Psychiatry 170:23-26

Borgstahl GE, Parge HE, Hickey MJ, Johnson MJ, Boissinot M, Hallewell RA, Lepock JR, Cabelli DE, Tainer JA (1996): Human mitochondrial manganese superoxide dismutase polymorphic variant Ile58Thr reduces activity by destabilizing the tetrameric interface. Biochemistry 35:4287-4297 
Casey DE (1991): Neuroleptic drug-induced extrapyramidal syndromes and tardive dyskinesia. Schizophr Res 4:109-120

Egan MF, Hyde TM, Albers GW, Elkashef A, Alexander RC, Reeve A, Blum A, Saenz RE, Wyatt RJ (1992): Treatment of tardive dyskinesia with vitamin E. Am J Psychiatry 149:773-777

Esteban J, Rosen DR, Bowling AC, Sapp P, MuKenna-Yasek D, O'Regan JP, Beal MF, Horvitz HR, Brown RH Jr (1994): Identification of two novel mutations and a new polymorphism in the gene for $\mathrm{Cu} / \mathrm{Zn}$ superoxide dismutase in patients with amyotrophic lateral sclerosis. Human Mol Genet 3:997-998

Grasbon-Frodl EM, Kösel S, Riess O, Müller U, Mehraein P, Graeber MB (1999): Analysis of mitochondrial targeting sequence and coding region polymorphisms of the manganese superoxide dismutase gene in German Parkinson disease patients. Biochem Biophys Res Commun 255:749-752

Guidot DM, McCord JM, Wright RM, Repine JE (1993): Absence of electron transport (Rho ${ }^{0}$ state) restores growth of a manganese-superoxide dismutase-deficient Saccharomyces cerevisiae in hyperoxia: Evidence for electron transport as a major source of superoxide generation in vivo. J Biol Chem 268:26699-26703

Gutteridge JM (1992): Iron and oxygen radicals in brain. Ann Neurol 32(Suppl):S16-S21

Guy W (ed) (1976): ECDEU Assessment Manual for Psychopharmacology. Publication ADM 534-537. Washington, DC, US Department of Health, Education and Welfare

Horrobin DF, Manku MS, Hillman H, Iain A, Glen M (1991): Fatty acid levels in the brains of schizophrenics and normal controls. Biol Psychiatry 30:795-805

Jeste DV, Kelsoe JR (1997): Schizophrenia, tardive dyskinesia, and D3 receptor gene variant: A new twist on dyskinesias? Mol Psychiatry 2:86-88

Kane JM, Smith JM (1982): Tardive dyskinesia. Arch Gen Psychiatry 39:473-481

Latimer PR (1995): Tardive dyskinesia: A review. Can J Psychiatry 40(Suppl 2):S49-S54

Lohr JB, Kuczenski R, Bracha HS, Moir M, Jeste DV (1990): Increased indices of free radical activity in the cerebrospinal fluid of patients with tardive dyskinesia. Biol Psychiatry 28:535-539

Lohr JB, Caligiuri MP (1996): A double-blind placebo-controlled study of vitamin E treatment of tardive dyskinesia. J Clin Psychiatry 57:167-173

Mahadik SP, Mukherjee S, Correnti EE, Scheffer R (1995): Elevated levels of lipid peroxidation products in plasma of drug-naive patients at the onset of psychosis. Schizophr Res 15:66

Malhotra AK, Goldman D (1999): Benefits and pitfalls encountered in psychiatric genetic association studies. Biol Psychiatry 45:544-550

Matsumoto T, Uchimura H, Hirano M, Kim JS, Yokoo H, Shimomura M, Nakahara T, Inoue K, Oomagari K (1983): Differential effects of acute and chronic adminis- tration of haloperidol on homovanillic acid levels in discrete dopaminergic areas of rat brain. Eur J Pharmacol 89:27-33

Miller CH, Simioni I, Oberbauer H, Schwitzer J, Barnas C, Kulhanek F, Boissel KE, Meise U, Hinterhuber H, Fleischhacker WW (1995): Tardive dyskinesia prevalence rates during a ten-year follow-up. J Nerv Ment Dis 183:404407

Mukherjee S, Mahadik SP, Scheffer R, Correnti EE, Kelkar H (1996): Impaired antioxidant defense at the onset of psychosis. Schizophr Res 19:19-26

Müller DJ, Ahle G, Alfter D, Krauss H, Knapp M, Marwinski K, Schulze TG, Weber T, Nöthen M, Maier W, Held T, Rietschel M (1998): Familial occurrence of tardive dyskinesia. Proceeding of the $6^{\text {th }}$ World Congress on Psychiatric Genetics, Bonn, Germany. Am J Med Genet 81:527

Ohmori O, Suzuki T, Kojima H, Shinkai T, Terao T, Mita T, Abe K (1998): Tardive dyskinesia and debrisoquine 4hydroxylase (CYP2D6) genotype in Japanese schizophrenics. Schizophr Res 32:107-113

Pall HS, Williams AC, Blake DR, Lunec J (1987) : Evidence of enhanced lipid peroxidation in the cerebrospinal fluid of patients taking phenothiazines. Lancet ii:596-599

Reddy R, Sahebarao MP, Mukherjee S, Murthy JN (1991): Enzymes of the antioxidant defense system in chronic schizophrenic patients. Biol Psychiatry 30:409-412

Schooler NR, Kane JM (1982): Research diagnoses for tardive dyskinesia. Arch Gen Psychiatry 39:486-487

Schwarts PJ, Reaume A, Scott R, Coyle JT (1998): Effects of over- and under-expression of $\mathrm{Cu}, \mathrm{Zn}$-superoxide dismutase on the toxicity of glutamate analogs in transgenic mouse striatum. Brain Res 789:32-39

Segman R, Neeman T, Heresco-Levy U, Finkel B, Karagichev L, Schlafman M, Dorevitch A, Yakir A, Lerner A, Shelevoy A, Lerer B (1999): Genotypic association between the dopamine D3 receptor and tardive dyskinesia in chronic schizophrenia. Mol Psychiatry 4:247-253

Sham PC, Curtis D (1995): Monte Carlo tests for associations between disease and alleles at highly polymorphic loci. Ann Hum Genet 59:97-105

Shimoda-Matsubayashi S, Matsumine H, Kobayashi T, Nakagawara-Hattori Y, Shimizu Y, Mizuno Y (1996): Structural dimorphism in the mitochondrial targeting sequence in the human manganese superoxide dismutase gene. Biochem Biophys Res Commun 226:561-565

Shimoda-Matsubayashi S, Hattori Y, Matsumine H, Shinohara A, Yoritaka A, Mori H, Kondo T, Chiba M, Mizuno Y (1997): MnSOD activity and protein in a patient with chromosome 6-linked autosomal recessive parkinsonism in comparison with Parkinson's disease and control. Neurology 49:1257-1262

Steen VM, Løvlie R, MacEwan T, McCreadie RG (1997): Dopamine D3-receptor gene variant and susceptibility to tardive dyskinesia in schizophrenic patients. Mol Psychiatry 2:139-145

Sweet RA, Mulsant BH, Gupta B, Rifai AH, Pasternak RE, McEachran A, Zubenko GS (1995): Duration of neuroleptic treatment and prevalence of tardive dyskinesia in late life. Arch Gen Psychiatry 52:478-486 
Toru M (1983): Seishinbunretsubyo no yakuri (Pharmacology in schizophrenia). Chu-gai Igakusha Co, Tokyo, Japan

Tsai G, Goff DC, Chang RW, Flood J, Baer L, Coyle JT (1998): Markers of glutamatergic neurotransmission and oxida- tive stress associated with tardive dyskinesia. Am J Psychiatry 155:1207-1213

Yamada K, Kanba S, Anamizu S, Onishi I, Ashikari G, Yagi G, Asai M (1997): Low superoxide dismutase activity in schizophrenia patients with tardive dyskinesia. Psychol Med 27:1223-1225 